\title{
CHEMICAL DEFENSE RESPONSES IN Eucalyptus globulus (Labill) PLANTS
}

\section{CHRISTIAN TRONCOSOA* , JOSÉ BECERRA ${ }^{B}$, MAGALIS BITTNER ${ }^{B}$, CLAUDIA PEREZ $^{B}$, KATIA SÁEZ ${ }^{\text {, }}$ MANUEL SÁNCHEZ-OLATE ${ }^{A, D}$ AND DARCY RÍOS ${ }^{A, D}$}

\author{
${ }^{a}$ Facultad de Ciencias Forestales, Universidad de Concepción, Concepción, Chile, Casilla 160-C, Tel.: 56-41-2204092, \\ ${ }^{b}$ Departamento de Botánica, Facultad de Ciencias Naturales y Oceanográficas, Universidad de Concepción, Casilla 160-C, Concepción, Chile \\ ${ }^{c}$ Departamento de Estadística, Facultad de Ciencias Físicas y Matemáticas, Universidad de Concepción, Casilla 160-C, Concepción, Chile \\ ${ }^{d}$ Centro de Biotecnología, Laboratorio de Cultivo de Tejidos Vegetales, Universidad de Concepción, Casilla 160-C, Concepción, Chile, Tel.: 56-41-2207241
}

(Received: November 16, 2010 - Accepted: March 3, 2011)

\begin{abstract}
This study evaluated the expression of defense compounds by the secondary metabolism of Eucalyptus globulus plants subjected to attacks by the insect Ctenarytaina eucalypti (blue gum psyllid) and abiotic mechanical damage using gas chromatography with flame ionization detection (GC-FID) and mass detection (MS). The results show that both biological and mechanical attacks activated defense responses in the plants. We identified 34 compounds in the leaves of the treated plants. In the case of the plants damaged by C. eucalypti, four of the compounds differed from those of the control: three oxygenated monoterpenes (borneol, exo-2-hydroxy cineole and thymol) and one quinone (6-acethyl-flaviolin). In the case of the mechanical damage, five compounds differed from the control: three sesquiterpenes (alloaromadendrene, eremophilene, and caryophyllene-oxide), borneol, and 6-acethyl-flaviolin. According to the results, different compounds are biosynthesized when faced with biotic and abiotic inductions, indicating a certain level of specificity in the response of the plants to different types of damage.
\end{abstract}

Keywords: E. globules, chemical defense, terpenes and quinones

\section{INTRODUCTION}

Plants can suffer abiotic as well as biotic damage, the former caused largely by hail and wind and the latter by microorganisms and insects. In both cases, the plants express a set of mechanical and physiological responses that could include, even as of the first incident, the activation of genes involved in defense $\mathrm{s}^{1,2}$

When a biotic agent attacks a plant, it synthesizes and transmits signals systemically to the entire plant ${ }^{3}$. These signals may be chemical (synthesis of oligosaccharides, abscisic acid, and systemin) or electric ${ }^{4,5}$. The plants respond to these signals by synthesizing secondary metabolites with antimicrobial, antifungal, and insecticidal activity ${ }^{6-8}$. These metabolites include terpenes, alkaloids, and phenols 9 . Although most of these metabolites play defensive roles against herbivores and pathogens, others act as allelopathic agents (affecting other plants), attract pollinators, and disperse seeds ${ }^{10,11}$.

A large number of secondary metabolites are volatile compounds that participate in the direct and indirect defense of the plants, acting as repellants or attracting the natural predators and controllers (enemy parasitoids) of the herbivores attacking the plants. The attraction of natural controllers by plants under insect attack has been demonstrated in numerous laboratory experiments $\mathrm{s}^{12-15}$ and under natural conditions $\mathrm{s}^{16-19}$. These works indicate that volatile compounds play an important role in plant-insect and plant-plant relations. This is done by producing a wide and varied group of volatile secondary metabolites, notably methyl jasmonate, methyl salicylate, and ethylene ${ }^{20-23}$. The diversity of these substances is explained by the fact that they are produced within the same biosynthetic pathways as the non-volatile secondary metabolites. The most relevant volatile compounds are terpenes, followed by compounds derived from fatty acids (saturated and nonsaturated hydrocarbons), benzenoids, and phenylpropanoids; sulfurated and nitrogenated substances have also been reported ${ }^{24,25}$. Many studies of plantinsect interactions deal with volatile secondary metabolites. These bioactive substances, apparently common in many species, include aldehydes, alcohols, and esters, amongst others ${ }^{26,27}$.

Although many of the secondary metabolites involved in plant defense have been traditionally considered to be either specifically active against pathogens (e.g. phytoalexins) or herbivores ${ }^{28}$, some can affect the performance of both pathogens and herbivorous insects ${ }^{29-31}$ and are considered to be "generalized defense compounds" 29 . Glucoside iridoids, a group derived from the monoterpenes found in more than 50 plant families, offer an interesting example of such compounds ${ }^{32}$; they have an antimicrobial effect against pathogenic bacteria and fungi $3^{3-36}$ as well as anti-alimentary properties for herbivorous insects in general ${ }^{37-39}$.
An important group of phytopathogenic insects that attack species of Eucalyptus belong to the genus Ctenarytaina. The best-known species of this genus, given the economic importance of some of its hosts, is Ctenarytaina eucalypti (blue gum psyllid), which has a marked preference for species such as E. maideni, E. pulverulenta, E. cinerea, E. nitens, and E. globulus. The latter is one of the most abundant species introduced to Chile by the forestry sector, with more than 458,611 hectares planted ${ }^{40-42}$.

Since 1999, when this psyllid first entered $\mathrm{Chile}^{43}$, different control strategies have been applied to avoid the damage produced by $C$. eucalypti, shuc as chemical control ${ }^{44-48}$ and bilogycal control schemes ${ }^{49,50}$, however both have presented poor results.

However, no studies have been aimed at understanding the inducible defense mechanisms of the species E. globulus, considering that the species of the genus Eucalyptus accumulate essential oils in the glands of their leaves that have shown antifungal, antimicrobial, and insecticidal activity ${ }^{51,52}$.

The present study attempts to elucidate a) whether the species Eucalyptus globulus (Labill) is capable of expressing internal defense responses when damaged by the insect $C$. eucalypti as well as, abiotic mechanical damage, b) identify the defense compounds and c) to determine whether the expression of defense compounds is selective, depending on the nature of the attack (biotic or abiotic).

\section{MATERIALS AND METHODS}

INSECT AND PLANT COLLECTION

To collect the necessary number of insects, we developed a $C$. eucalypti rearing system. The system consisted of a greenhouse $(70 \mathrm{~cm} \times 140 \mathrm{~cm}$ x $80 \mathrm{~cm})$ built with PVC tubes $(20 \mathrm{~mm} \varnothing)$ and plastic $(0.2 \mathrm{~mm}$ thick). The greenhouse was stocked with 70 plants of E. globulus six-month-old, from the nursery of the Facultad de Ciencias Forestales, Universidad de Concepción. In the greenhouse, the plants were kept in bags with a capacity for $1000 \mathrm{~mL}$ of organic substrate. A watering system was installed over each bag and the plants were watered for $3 \mathrm{~min}$ (approx. $400 \mathrm{~mL}$ ) every four hours (9:00, 13:00, 17:00) during the day.

Insects were collected from a heavily infested $E$. globulus plantation on the Malven farm ( $37^{\circ} 42^{\prime} 6,49^{\prime} \mathrm{S}-72^{\circ} 21^{\prime} 28,83^{\prime \prime W}$, datum 1984), Bío Bío Region; the adults (200 males and 200 females) corresponded to those described by Maskell ${ }^{53-55}$. The psyllids were released over the plants in the rearing system, and we obtained new generations of insects after 23 days at average minimum and maximum temperatures of $14^{\circ} \mathrm{C}$ and $24{ }^{\circ} \mathrm{C}$.

TREATMENTS

Two treatments (T1 and T2) plus a control (T0) were assayed. Each 
treatment was applied to 27 plants of E. globulus four-month-old from the nursery of the Facultad de Ciencias Forestales, Universidad de Concepción.

Treatment T1: consisted in exposing the apical sections of the plants to an attack by five specimens of the insect C. eucalypti for 24 hours, followed by 24 hours with no attack.

Treatment T2: five microneedles $(0.33 \mathrm{~mm} \times 12.7 \mathrm{~mm})$ was inserted into the plants through the venation of the leaves and the stalk of the apical section for 24 hours, followed by 24 hours without the insertion of the microneedle. All treatments were applied nine times and chromatographic analyses were done after the third, sixth, and ninth applications.

The insects were handled and placed on the plants with pincers and paper cylinders $(4 \mathrm{~cm}$ diameter $\times 10 \mathrm{~cm}$ long) closed at one end with tulle. The insects were caught with the help of an entomological aspirator and later transferred to the paper cylinders, which were then tied to the apical sections of the plants.

OBTAINING AND IDENTIFICATION OF COMPOUNDS

Once the third, sixth, and ninth inductions of each treatment were completed, two leaves were extracted from the apical section of each plant in each treatment. The leaves were sectioned manually and placed in vials with 50 $\mathrm{mL} n$-hexane and stored at $4^{\circ} \mathrm{C}$ for 48 hours, for the extraction of compounds. Later, chromatographic profiles were obtained in a gas chromatograph Agilent 6890 A with an FID detector and a chromatograph Hewlett Packard Mod. 5890 Series II (California, USA) with a mass detector HP model 5972. The gas carrier was helium, with a flux of $1 \mathrm{~mL}^{*} \mathrm{seg}^{-1}$; injector temperature was $275^{\circ} \mathrm{C}$; detector temperature was $300^{\circ} \mathrm{C}$; and the program for oven temperature was $60^{\circ} \mathrm{C}$ for the first $5 \mathrm{~min}$, increasing $10^{\circ} \mathrm{C}$ per minute until reaching $275^{\circ} \mathrm{C}$, with a final time of $15 \mathrm{~min}$. A $30-\mathrm{m}$ chromatographic fused silica column HP-5MS (J\&W Scientific) with an internal diameter of $0.25 \mathrm{~mm}$ and a phase thickness of $0.25 \mu \mathrm{m}$ was used to compare the retention times with commercial standards (SIGMA) and the database EPA-NIST 98 was used to compare the mass spectra.

\section{RESULTS AND DISCUSSION}

Thirty-four compounds were identified (Table 1), mainly mono- and sesquiterpenes and, in lower amounts, some hydrocarbons and a quinone. In treatment $\mathrm{T} 1$ (induction by the insect $C$. eucalypti), the plants expressed four compounds different from the control: borneol, exo-2-hydroxy cineole, thymol, and 6-acethyl-flaviolin. In treatment T2 (mechanical induction), the plants expressed five compounds that differed from the control: borneol, alloaromadendrene, eremophilene, caryophyllene-oxide, and 6-acethylflaviolin. The expression of different compounds and in different concentrations, when faced with mechanical and insect-induced harm, coincides with that found for lima beans, Phaseolus lunatus by Mithöfer et al. (2005) ${ }^{56}$ and in both tomato (Solanum lycopersicum) and Arabidopsis (Arabidopsis thaliana) by Howe and Jander $(2008)^{57}$.

The relevant importance of these results implies that the secondary metabolic defenses can be induced and that further studies can decipher the mechanisms by which the species E. globulus is able to establish an immune system and that these principles of plant immunology, could be applied to any tree species, leading to the production of forest species with a certificate of resistance to injurious factors that most affect their production.

It is highly likely that plants respond to aggression, be it biotic or abiotic, with a group of general compounds and that the plants also release other compounds with a higher degree of selectivity. A greater expression of $\alpha$-pinene was found in the plants induced with C. eucalypti (T1) than in those of the control (T0) and the mechanical treatment (T2), thereby ratifying the effect of the monoterpenes as repellent, anti-alimentary, and insecticidal agents with larvicidal and acaricidal properties reported for the essential oils of Myrtaceae, which are rich in monoterpenes ${ }^{58,59}$.

In both treatments $\mathrm{T} 1$ and $\mathrm{T} 2$, the expression of cineole was lower than in the control (T0). Although this compound has a proven repellent effect on insects and some herbivorous mammals ${ }^{60}$, cineole production occurs as part of a complex physiological cost-benefit action in the exposed plants that activates a certain compound in detriment to others ${ }^{61}$. A greater concentration of $\alpha$-terpynil acetate was found in the entomological treatment (T1), as compared to the mechanical and control treatments; this compound is found within the complex of terpenoids that act as anti-alimentary agents, toxins, and growth regulators for insects ${ }^{62}$.
Table 1. Identification of compounds with GC-MS.

\begin{tabular}{|c|c|c|c|c|}
\hline Peak & & Area & & \multirow{3}{*}{ Name of compound } \\
\hline \multirow[t]{2}{*}{ \# } & T0 & $\mathrm{T} 1$ & $\mathrm{~T} 2$ & \\
\hline & Control & $\begin{array}{l}\text { Induction by } \\
\text { C. eucalypti }\end{array}$ & $\begin{array}{l}\text { Mechanical } \\
\text { induction }\end{array}$ & \\
\hline \multicolumn{5}{|c|}{ Monoterpene hydrocarbons } \\
\hline 1. & + & + & + & $\alpha$-thujene \\
\hline 2. & + & + & + & $\alpha$-pinene \\
\hline 3. & + & - & - & camphene \\
\hline 4. & + & + & + & $\beta$-pinene \\
\hline 5. & + & + & + & $\beta$-terpinene \\
\hline 6. & + & + & + & carene \\
\hline 7. & + & + & + & p-cymene \\
\hline
\end{tabular}

\begin{tabular}{lllll}
\multicolumn{7}{l}{ Oxygenated monoterpenes } \\
8. & + & + & + & cineole \\
9. & + & + & + & linalool \\
10. & - & + & + & borneol \\
11. & + & - & + & phenylethyl alcohol \\
12. & + & + & + & $\alpha$-terpineol \\
13. & - & + & - & exo-2-hydroxy cineole \\
14. & + & - & - & $\beta$-terpineol \\
15. & - & + & - & thymol \\
16. & + & + & - & $\alpha$-terpinyl-acetate
\end{tabular}

Sesquiterpene hydrocarbons

$\begin{array}{lllll}17 . & + & - & - & \alpha \text {-gurjunene } \\ 18 . & + & + & + & \text { aromadendrene } \\ 19 . & - & - & + & \text { alloaromadendrene } \\ 22 . & - & - & + & \text { eremophilene }\end{array}$

\begin{tabular}{|c|c|c|c|c|}
\hline \multicolumn{5}{|c|}{ Oxygenated sesquiterpenes } \\
\hline 20. & + & + & + & epiglobulol \\
\hline 21. & + & + & + & spathulenol \\
\hline 23. & + & + & + & globulol \\
\hline 24. & - & - & + & caryophyllene-oxide \\
\hline 25. & + & + & + & ledol \\
\hline 26. & + & + & + & $\gamma$-eudesmol \\
\hline 27. & + & + & + & $\alpha$-eudesmol \\
\hline 28. & + & + & + & $\beta$-eudesmol \\
\hline
\end{tabular}

\begin{tabular}{|c|c|c|c|c|}
\hline \multicolumn{5}{|c|}{ Hydrocarbons } \\
\hline 29. & + & + & + & tetradecanal \\
\hline 30. & + & + & + & tetradecanone \\
\hline 31. & + & + & + & pentadecanal \\
\hline 32. & + & + & + & heptadecanona \\
\hline 33. & + & + & + & nonadecanona \\
\hline \multicolumn{5}{|c|}{ Quinones } \\
\hline 34. & - & + & + & 6-acethyl-flaviolin \\
\hline
\end{tabular}

NOTE: (+) Compound detected, (-) Compound not detected

The oxygenated sesquiterpene and hydrocarbons detected in the treated plants (both mechanically and entomologically) selectively express defense compounds depending on the nature of the perceived aggression; these allelochemical compounds have an important anti-alimentary function in insects ${ }^{63}$.

Hydrocarbons act as effective repellents, whereas quinones play a role in reducing digestibility in insects ${ }^{64}$, the expression of both compounds plays an important role within the plant's defense strategies.

\section{CONCLUSIONS}

We found that the E. globulus plants induced biotically and abiotically through treatments T1 and T2 expressed defense compounds coming from the secondary metabolism. These consisted mainly of mono- and sesquiterpenes as well as some hydrocarbons and a quinone.

The plants expressed some common compounds (e.g. borneol and 6-acethyl-flaviolin) when faced with the two types of induction (mechanical and entomological) as well as specific compounds (exo-2-hydroxy cineole and 
thymol with entomological induction and alloaromadendrene, eremophilene, and caryophyllene-oxide with mechanical induction), showing that the plants are selective when expressing defense compounds depending on the nature of the attack (entomological or mechanical).

When the expression of certain compounds increases, the expression of others is depressed, manifesting a compensatory effect in the biochemical equilibrium of the plant.

\section{ACKNOWLEDGEMENTS}

We thank CONICYT and the Graduate Council of the Universidad de Concepción for funding granted during the development of C.T.'s doctoral studies and Anillo Project ADI-38.

\section{REFERENCES}

1. D. J. Bowles, Annual review of biochemistry, 59, 873, (1990).

2. M. Frey, C. Stettner, P. W. Paré, E. A. Schmelz, J. H. Tumlinson, A. Gierl, Natl. Acad. Sci USA, 97, 14801, (2000).

3. L. Mattiacci, B. A. Rocca, N. Scascighini, M. D'alessandro, A. Hern, S. J. Dorn, Chem. Ecol., 11, 2233, (2001).

4. P. W. Paré, J. H. Tumlinson, Plant Physiol, 121, 325, (1999).

5. F. Gozzo, Journal of Agricultural and Food Chemistry, 51, 4487, (2003).

6. E. Shaaya, M. Kostjukovski, J. Eilberg y C. Sukprakarn, J. Stored Prod. Res., 33, 7, (1997).

7. B. H. Lee, W. S. Choi, S. E. Lee, B. S. Park, Crop Protection, 20, 317, (2001).

8. A. L. Tapondjou, C. Adler, D. A. Fontem, H. Bouda y C. Reichmuth, J. Stored Prod. Res., 41, 91, (2005).

9. L. Taiz, E. Zeiger, Plant Physiology, 4th Edition. Chapter 13. Sinauer Associates, Inc. 2006.

10. D. A. Levin, Ann Rev. Ecol. Syst., 7, 121, (1976).

11. A. Cronquist, Plant Syst Evol., 1, 179, (1977).

12. Y. Du, G. M. Poppy, W. Powell, J. A. Pikett, L. J. Wadhams, C. M. Woodcock, J. Chem. Ecol., 24, 1355, (1998).

13. M. A. Birkett, K. Chamberlain, E. Guerrieri, J. A. Pikett, L. J. Wadhams, T. Yasuda, J. Chem. Ecol., 29, 1589, (2003).

14. T. Bukovinszky, R. Gols, M. A. Posthumus, L. E. M. Vet, J. C. Lenteren, J. Chem. Ecol., 31, 461, (2005).

15. Y-G Lou, B. Ma, J-A Cheng, J. Chem. Ecol., 31, 2357, (2005).

16. T. Shimoda, J. Takabayashi, W. Ashihara, A. Takafuji, J. Chem. Ecol., 23, 2033, (1997).

17. J. S. Thaler, Nature, $399,686,(1999)$.

18. A. Kessler, I. T. Baldwin, Science, 291, 2141, (2001).

19. M. Heil, J. Ecol., 92, 527, (2004).

20. A. B. Bleecker, H. Kende, Annual Rev. Cell Dev. Biol., 16, 1, (2000).

21. L. L. Walling, J. Plant Growth Reg., 19, 195, (2000).

22. G. L. De Bruxelles, M. R. Roberts, Crit. Rev. Plant Sci., 20, 487, (2001).

23. J. A. Gatehouse, New Phytol., 156, 145, (2002).

24. J. T. Knudsen, L. Tollsten, L. G. Bergstrom, Phytochemestry, 33, 253 , (1993).

25. N. Dudareva, E. Pichersky, J. Gershenzon, Plant Physiol., 135, 1893, (2004).

26. T. C. J. Turlings, J. H. Loughrin, P. J. McCall, U. S. R. Rose, W. J. Lewis, J. H. Tumlinson, Proceedings of the National Academy of Sciences of the USA 92(10), 4169, (1995).

27. N. Dudareva, E. Pichersky, Plant Physiol., 135, 1893, (2000).

28. J. B. Harborne, Nat. Prod. Reports, 10, 327, (1993).

29. V. A. Krischik, Environ. Entomol., 17, 476, (1988).

30. R. Hammerschmidt, J. C. Schultz, Rec. Adv. Phytochem., 30, 122 , (1996).

31. R. Karban, I. T. Baldwin, Trends in Ecology \& Evolution, 13(2), 83, (1998).

32. S. R. Jensen, in "Ecological Chemistry and Biochemistry of Plant Terpenoids", J.B. Harborne and F.A Thomas-Barberan, eds. (Clarendon Press, Oxford), 1991; pp. 133

33. K. Ishiguro, M. Yamaki, S. Takagi. Yakugaku Zasshi 102, 755, (1982).

34. W. G. Van der Sluis, J. M. Van der Nat, R. P. Labadie, J Chromatogr., 259, 522, (1983).

35. F. R. Stermitz, Biological active natural products, symposium 380
American Chemical Society, Washington D.C., 397, (1988).

36. H. B. Marak, A. Biere, J. M. M. Van Damme, Chemoecology., 12, 185, (2002).

37. M. D. Bowers, G. M. Puttick, J Chem Ecol., 14, 319, (1988).

38. M. D. Bowers, G. M. Puttick, Ecol Entomol., 14, 247, (1989).

39. M. D. Bowers, Iridoid glycosides. in G. A. Rosenthal and M. R. Berenbaum, Eds. Academic Press, Orlando, FL. 1991; pp. 297-325.

40. W. M. Ciesla, M. Diekmann and C. A. J. Putter, Technical guidelines for the safe movement of germplasm No. 17. Eucalyptus spp. 66 p. FAO/ IPGRI, Rome, Italy, (1996).

41. J. T. Kliejunas, B. M. Tkacz, H. H. Burdsall, H. Harold, G. A. DeNitto, A. Eglitis, Gen. Tech. Rep. FPL-GTR-124. 134 p. United States Department of Agriculture, Forest Service, Forest Products Laboratory, Madison, Wisconsin, USA, (2001).

42. INFOR-MINAGRI, Informe Técnico, "Superficie de plantaciones forestales de Coquimbo a Aysén; e inventario de plantaciones PYMP regiones Bío Bío y Araucanía, actualización a diciembre de 2008", (2009).

43. T. Olivares, Gayana (Concepc.), vol., 64, 239, (2000).

44. F. Bertaux, M. Phalip, M. Martínez and J. C. Schumacher, Phytoma-La Defense des Vegetaux., 487, 48, (1996).

45. D. L. Dahlsten, D. L. Rowney, W. A. Copper, R. L. Tassan, W. E. Chaney, K. L. Robb, Calif. Agric., 52, 31, (1998).

46. J. C. Malausa, Biofutur., 176, 34, (1998).

47. M. P. Chauzat, 151 p. Ph.D. diss. National University of Ireland, Dublin, Ireland, (2000).

48. F. Sáis, A. Giambruno, P. Jeveles, Rev. Chil. Entomol., 29, 19, (2003).

49. F. Sáiz, M. MacLean, Rev. Chil. Entomol., 30, 45, (2004).

50. F. Rodríguez, F. Sáiz, Agric. Téc., 66(4), 342, (2006).

51. H. Ramezani, H. P. Singh, D. R. Batish and R. K. Kohli, Fitoterapia, 73, $261,(2002)$.

52. G. Sacchetti, S. Maietti, M. Muzzoli, M. Scaglianti, S. Manfredini, M. Radice And R. Bruni, Food Chem., 91, 621, (2005).

53. R. Zondag, Forest Reseach Institute New Zealand Forest Service, 53, 3, (1982).

54. D. Burckhardt, A review. Trends Agr. Sci. Entomol., 2, 173, (1994)

55. D. Burckhardt, Rev. Chilena. Ent., 21, 57, (1994).

56. A. Mithöfer, G. Wanner, W. Boland, Plant Physiol. 137, 1160, (2005).

57. G. Howe, G. Jander, Annual Rev. Plant Biol., 59, 41, (2008).

58. Alejandro Urzúa, Rocío Santander, Javier Echeverria, Nancy cabezas, Sara M. Palacios y Anina Rossi. J. Chil. Chem. Soc., 55, No 3 (2010).

59. Magalis L. Bittner, María E. Casanueva, Cecilia C. Arbert, Milenko A. Aguilera, Victor J. Hernández and José V. Becerra. J. Chil. Chem. Soc., $53, \mathrm{~N}^{\circ} 1(2008)$

60. V. Corbel, M. Stankiewicz, C. Pennetier, D. Fournier, J. Stojan, E. Girard, M. Dimitrov, J. Molgo, J. Hougard and B. Lapied, BMC Biology, 7, 47, (2009).

61. M. Dicke, M. W. Sabelis, Functional Ecology, 2,131, (1988).

62. D. A. Wheeler and M. B. Isman, Entomol. Exp. Appl., 98, 9, (2001).

63. J. A. Pickett, Ecological Chemistry and Biochemistry of Plant Terpenoids. Harborne, J.B. \& Tomas-Barberan, F.A. (Eds). Proc. Phytochemistry Soc. Europe, Clarendon Press, Oxford, 1991; 297-313.

64. G. W. Felton, K. K. Donato, R. M. Broadway and S. S. Duffey, J. Insect Physiol. 38, 277, (1992). 